\title{
A cross sectional study of nutritional status among first semester adolescents of a polytechnic college in North Karnataka, India
}

\author{
Gowri Shankar \\ Professor, Dept. of Community Medicine, S.N. Medical College, Navanagar, Bagalkot, Karnataka, India \\ *Corresponding Author: \\ Email: drgowrijnmc@gmail.com
}

\begin{abstract}
Introduction: Adolescence is a period of rapid growth \& maturity, both physiologically \& psychologically. Adult weight of $35 \%$ \& 11-18\% of adult height is acquired during adolescent age. Nutrition has a key role to support this rapid growth and development. Objective of the study: To assess nutritional status among first semester adolescents of a Polytechnic College in North Karnataka.

Methodology: All the new admissions of a polytechnic college in North Karnataka for the year 2015 were included in the study after Ethical Clearance and permission from the Principal of the college. Age of each student was determined by date of birth. Weight was recorded by a portable weighing machine without footwear. The standing height was recorded by asking the student to stand against the wall, heels together without shoes. The height was measured with the help of a flexible measuring tape graduated in centimeters and inches. Body mass index was calculated using the formula weight in kilogram/Height in metre. ${ }^{2}$ Each student classified according to WHO BMI for age and Height for age. Data was analyzed using percentages and Fischer exact test.

Results: Out of 307 admissions of 2015, 214 (69.71\%) were boys and 93 (30.29\%) were girls. Majority (69.71\%) were between $17-19$ years and $25.08 \%$ were between $15-16$ years. Students $>20$ years were $5.21 \%$. Out of 291 adolescent students between 15 - 19 years, thinness was observed in $24.74 \%$ and severe thinness in $19.59 \%$. Regarding height for age, stunting was observed in $18.90 \%$ and severe stunting in $2.06 \%$.
\end{abstract}

Conclusion: National nutrition mission could be the only answer to solve thinness and stunting in adolescents.

Keywords: Stunting, Thinness, Adolescents.

\section{Introduction}

Adolescence is a period of rapid growth \& maturity, both physiologically \& psychologically. Adolescent group requires a lot of support and right guidance in terms of physical growth, sexual maturation, optimum nutrition \& sound mental help. Adult weight of $35 \%$ \& $11-18 \%$ of adult height is acquired during adolescent age. Nutrition has a key role to support this rapid growth and development.

Adolescence is a window of opportunity to prevent the onset of nutrition related chronic diseases in adult life. ${ }^{1}$ Under nutrition in the early teens is directly linked to lifestyle related diseases of adulthood like diabetes, hypertension \& cardiovascular disease. ${ }^{2}$

Adolescents are independent in making their food choices. Peer group, media and body image play important roles in determining their food choices. ${ }^{3}$

The large number of moderately or severely underweight children and adolescents in 2016 (75 million girls and 117 million boys) still represents a major public health challenge, especially in the poorest parts of the world.

This reflects the threat posed by malnutrition in all its forms, with there being underweight and overweight young people living in the same communities. ${ }^{4}$

Anthropometry is the one most important criterion to monitor growth assessment. Anthropometric data will help identify stunting, underweight, overweight and obesity. ${ }^{1}$
The objective of the study was to assess nutritional status among first semester adolescent students of a Polytechnic College in North Karnataka.

\section{Materials and Methods}

This cross sectional study was done in all the June 2015 admissions of the polytechnic college after Institutional Review Board clearance and permission from the Principal of the college. After informed consent from each student, data was collected. Age of each student was determined by date of birth. Weight was recorded by a portable weighing machine without footwear. The standing height was recorded by asking the student to stand against the wall, heels together without shoes. Body mass index was calculated using the formula weight in kilogram/Height in metre. ${ }^{2}$ Each student classified according to WHO body mass index for age and height for age and categorized into thin (-2 Standard Deviation) severe thin (-3 Standard Deviation), stunted (-2 Standard Deviation) and severely stunted (-3 Standard Deviation), overweight and obese. Data was analyzed using percentages, and Fischer exact test.

\section{Results}

Out of 307 admissions of 2015, $214(69.71 \%)$ were boys and $93(30.29 \%)$ were girls. Majority $(69.71 \%)$ were between $17-19$ years and $25.08 \%$ were between 15 - 16 years. Students more than 20 years were $5.21 \%$. 
It was observed that majority of the male and female students were from urban areas. $(60.26 \%)$

Overall, $51.89 \%$ of the students had normal body mass index, thinness was seen in $24.74 \%$ of the students and severe thinness in $19.59 \%$. Overweight was observed in $3.44 \%$ of the students. Severe thinness and thinness was more in the male students. (Fischer exact test 0.02) (Graph 1)

Majority of the adolescents had normal height for age $(79.04 \%)$ Stunting was observed in $18.9 \%$ and severe stunting in $2.06 \%$ of the students. It was observed that stunting was more in females $(21.98 \%)$ and severe stunting more in males $(2.50 \%)$ (Graph 2$)$ (Fischer exact test $=0.48$ )

Stunting (34.21\%) and severe stunting $(2.63 \%)$ was observed more in female students from rural areas compared to urban areas. (Graph 3) (Fischer exact test 0.03). Regarding body mass index, thinness was observed more in female students from rural areas whereas overweight was more in female students from urban areas. (Graph 4) (Fischer exact test $=0.66$ )

Among adolescent males, stunting and severe stunting was observed more in the boys from rural areas than those residing in urban areas. (Graph 5) (Fischer exact test $=0.39$ ) Regarding severe thinness, it was seen more in adolescent boys from rural areas whereas overweight and obesity was more in urban boys. (Graph 6) $($ Fischer exact test $=0.47)$

Stunting was observed in $19.48 \%$ adolescents in 15 to 16 years age group and in $18.70 \%$ between 17 to 19 years of age. Severe stunting was seen in $2.80 \%$ adolescents between 17 to 19 years of age. (Fischer exact test $=4.35$ )

Thinness was observed in $26.17 \%$ adolescents between 17 to 19 years of age. In $31.17 \%$ adolescents between 15 to 16 years, severe thinness was observed. (Fischer exact test $=0.05$ )

\section{Graph 1: Sex wise distribution according to BMI}

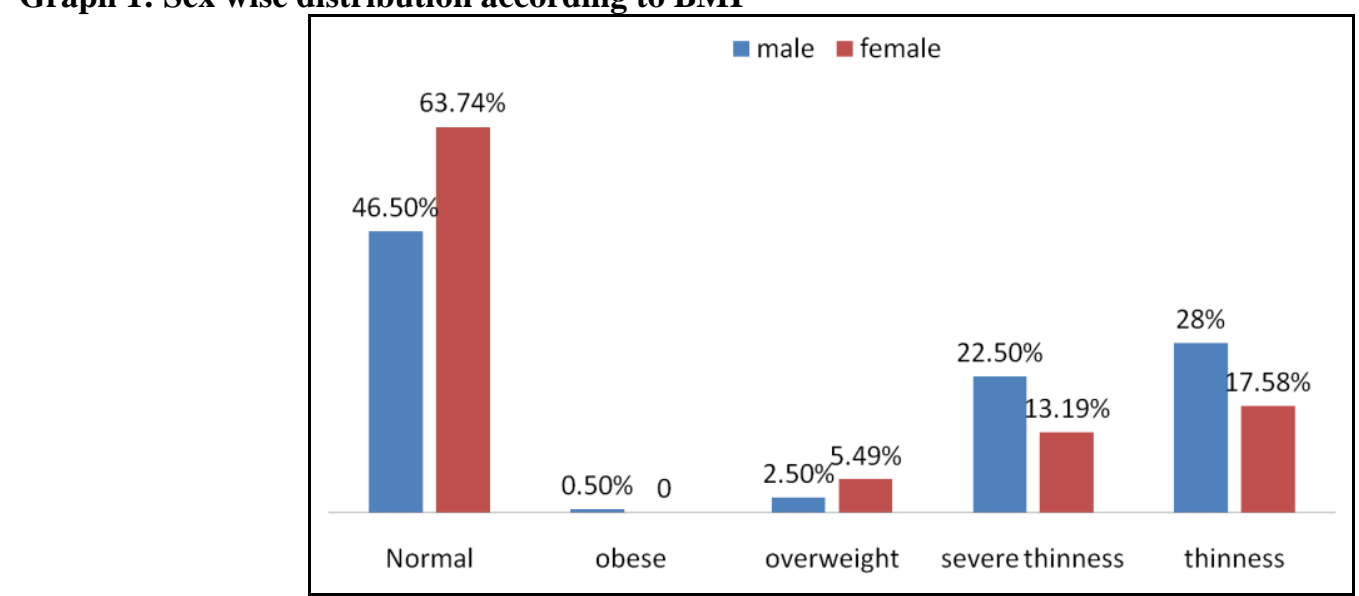

Fischer exact test $=\mathbf{0 . 0 2}$

Graph 2: Sex wise distribution according to height for age

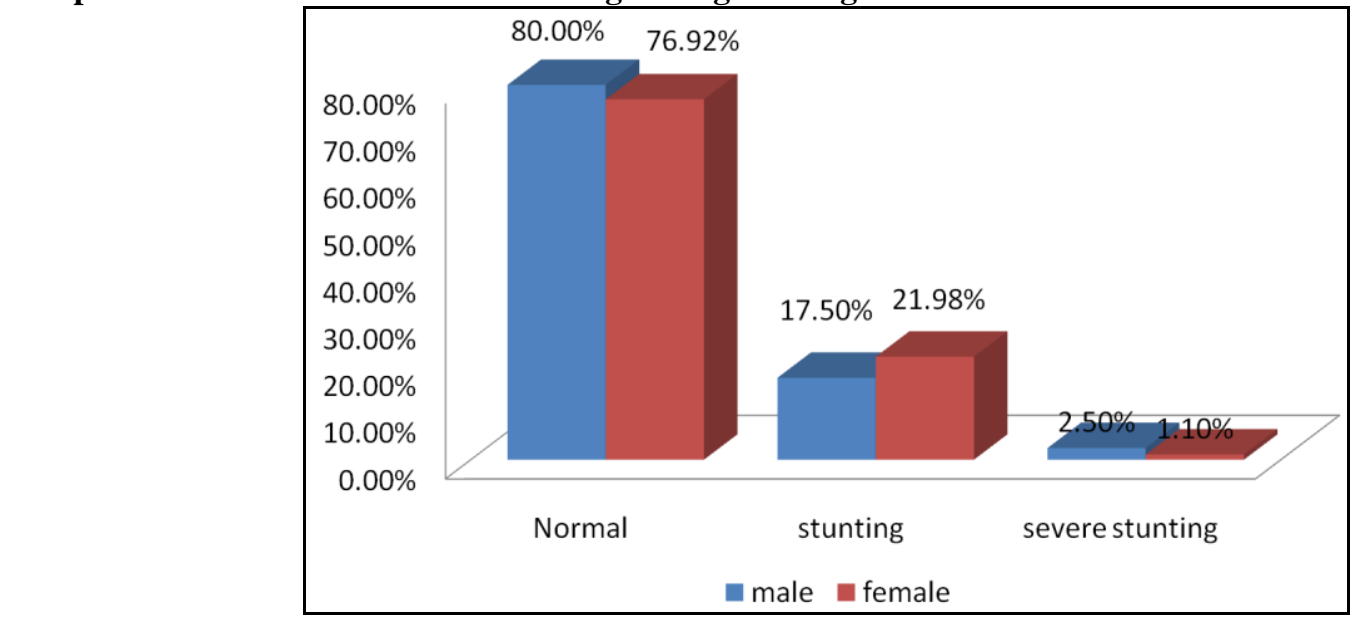

Fischer exact test $=0.48$ 
Graph 3: Distribution of adolescent females according to height for age

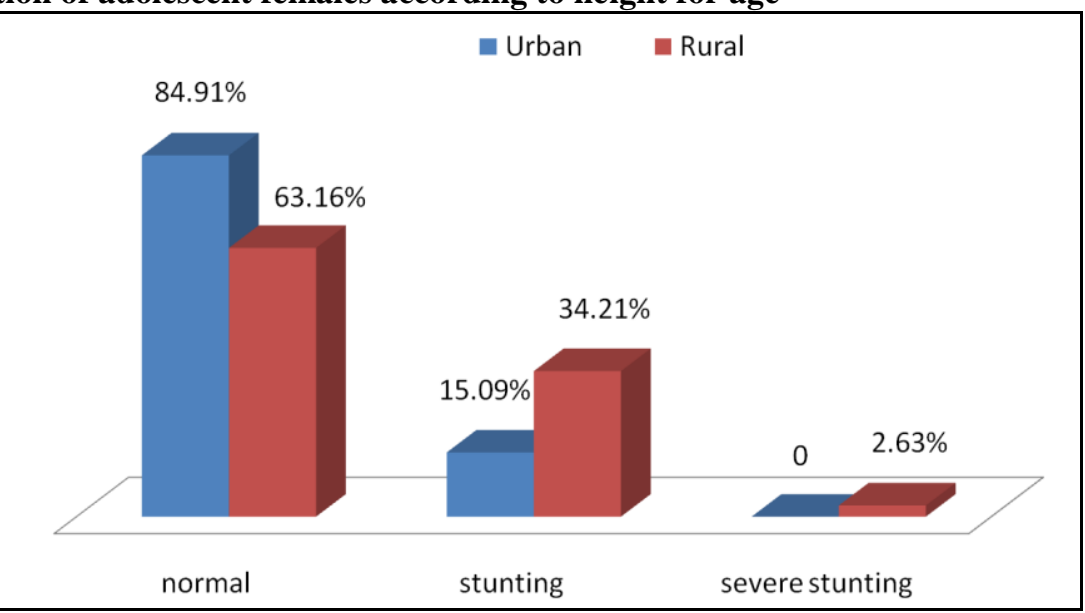

Fischer exact test $=0.03$

Graph 4: Distribution of adolescent females according to body mass index

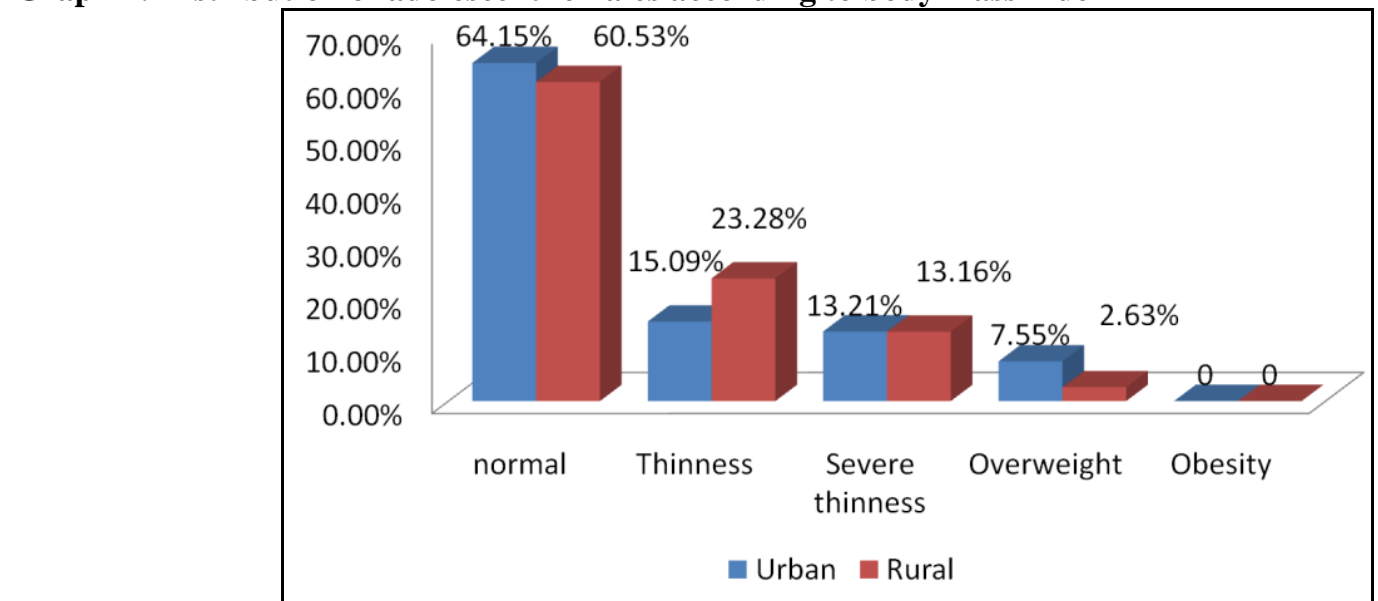

Fischer exact test $=0.66$

Graph 5: Distribution of adolescent males according to height for age

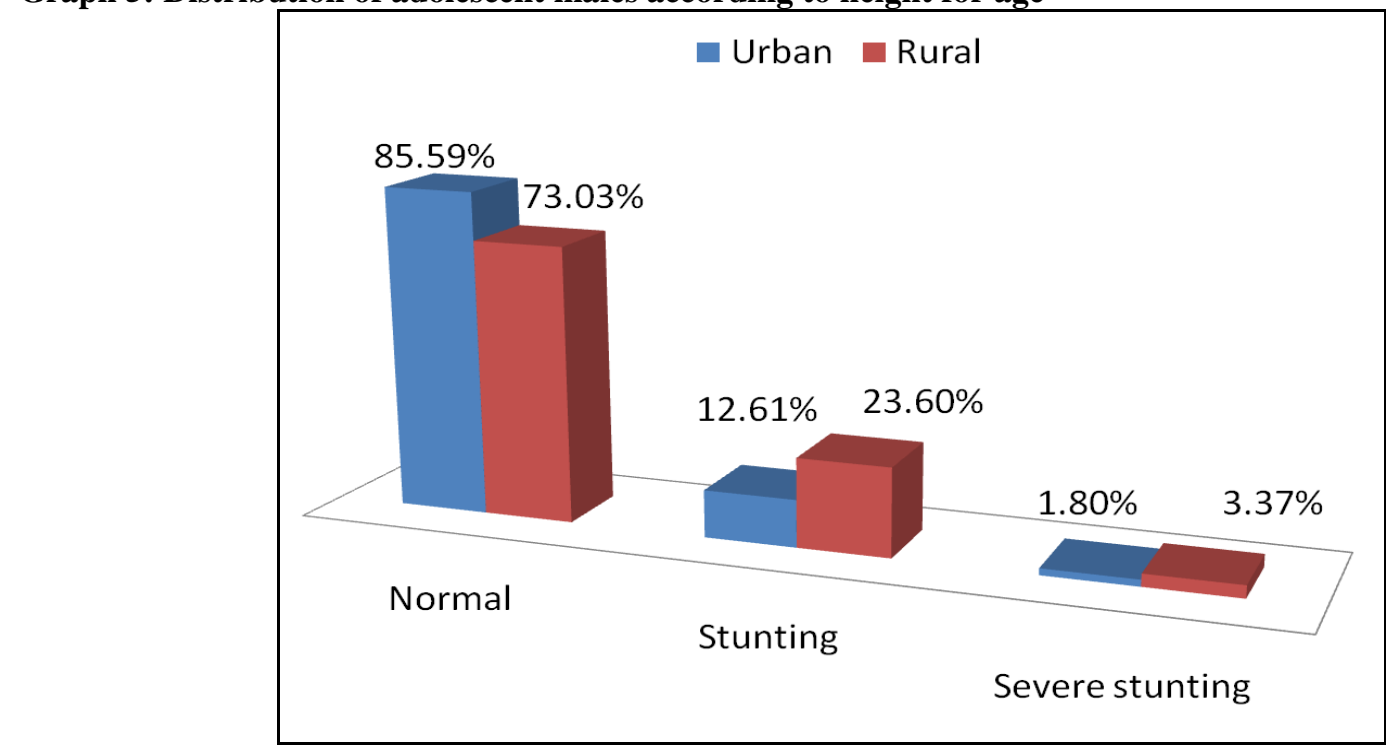

Fischer exact test $=\mathbf{0 . 3 9}$ 
Graph 6: Distribution of adolescent males according to body mass index

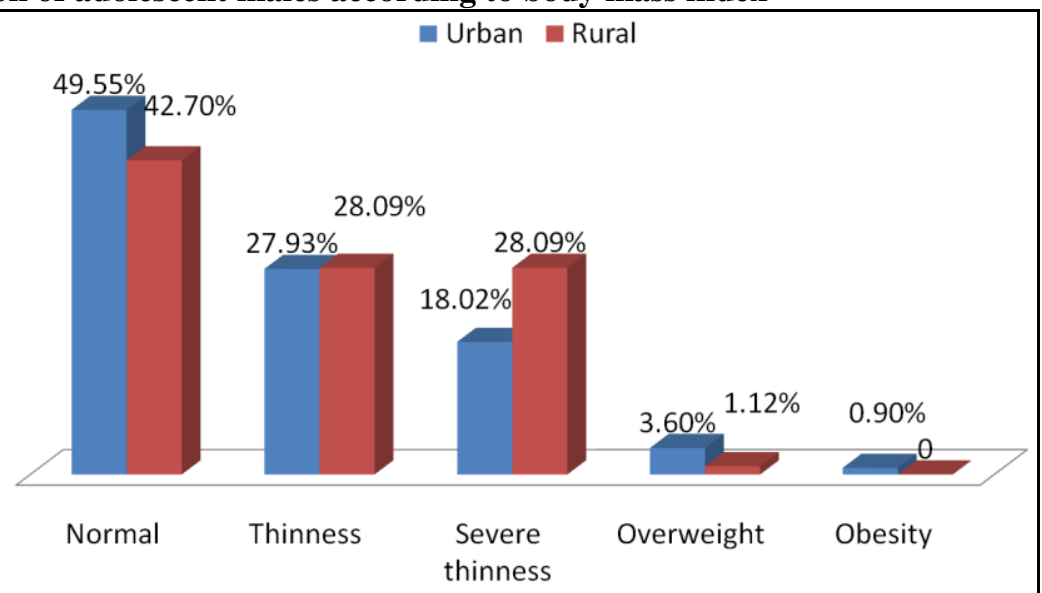

Fischer exact test $=\mathbf{0 . 4 7}$

\section{Discussion}

Body mass index measurements of adolescents are recommended wherever \& whenever feasible, irrespective of the type of nutrition problems to be expected. The consequences of stunting \& malnutrition are delay in maturation, especially in girls, reduction of work capacity and higher risk of infectious diseases. Whether too high or too low, inappropriate BMI in adolescents should trigger an appropriate response from health care providers. ${ }^{1}$

Overall, $51.89 \%$ of the students had normal body mass index; thinness was seen in $24.74 \%$ and severe thinness in $19.59 \%$. Majority of the adolescents had normal height for age (79.04\%) stunting was observed in $18.9 \%$ and severe stunting in $2.06 \%$ of the students. In contrast, in a study done in Ethiopia, overall prevalence of thinness was $55 \%$ and stunting was $25.5 \% .^{5}$

Severe thinness and thinness was observed more in male students than female students and was found to be statistically significant. Similar findings have been reported worldwide. ${ }^{4}$ This could be attributed to the growth spurt in adolescent boys.

Stunting and severe stunting was observed more in female adolescent students from rural areas compared to urban areas and was statistically significant. This finding is similar other studies. ${ }^{6,7}$ In a study done in West Bengal, $70.21 \%$ of the rural adolescent girls of 17 years age were stunted. ${ }^{8}$ In another study done in rural adolescent girls, stunting was seen in 58.4\%. ${ }^{9}$ This indicates chronic malnutrition in girls from rural areas and the socio cultural and environmental factors responsible for the same. The first 3 years of life in a child is most crucial to prevent stunting and indicates the outcome of integrated child development scheme and mid day meal programs in the area.

In this study, thinness was more in female students from rural areas and is comparable to another study. ${ }^{5}$ In contrast, overweight was seen more in female students from urban areas. This finding could be attributed to food gap in rural areas and their lifestyle whereas in urban areas it could be attributed to sedentary lifestyle and availability of fast foods.

Similar findings were observed in male adolescent students from rural areas regarding stunting and severe stunting and also severe thinness and overweight and obesity. In the most recent study published in "The Lancet" on $10^{\text {th }}$ October, 2017, it was observed that India had the highest prevalence of moderate and severe underweight throughout the four decades $24.4 \%$ of girls \& $39.3 \%$ of boys in 1975 and $22.7 \%$ \& $30.7 \%$ in 2016). 97 million of the world's moderately or severely underweight children and adolescents lived in India in 2016. Prevalence was more in rural areas and among adolescent boys. Prevalence of thinness exceeded that of stunting. ${ }^{4}$ This is quite a dismal finding and effective action should be brought about to decrease the prevalence of stunting and thinness in adolescents by reaching early adolescent age group.

About $20 \%$ of students between 15 to 16 years and 17 to 19 years were stunted. Severe stunting was observed in $2.80 \%$ students between 17 to 19 years. This indicates the need to bridge the food gap in the school years itself as stunting cannot be reversed beyond the adolescent age.

Severe thinness was observed more in students between 15 to 16 years of age and thinness was more between 17 to 19 years of age. This could be attributed to their growth spurt in early adolescence. Knowledge regarding protein energy foods should be introduced during the school years. A growth chart is to be maintained for every child up to the age of 18 years so that early interventions can be taken by the family and health care providers concerned.

\section{Conclusion}

National nutrition mission could be the only answer to solve thinness and stunting in adolescents.

\section{Conflict of Interest: Nil}


Acknowledgement: The author acknowledges the Principal and staff of BVV Sangha Polytechnic College and the students in conducting the study. The author also acknowledges the medico social workers of Urban health training center and the interns during the study period.

\section{References}

1. Madhu Sharma. Nutrition for the adolescent. In: Basic pediatric nutrition. $1^{\text {St }}$ edn. New Delhi. Jaypee Brothers medical publishers (P) Ltd 2009:83.

2. Elizabeth KE. Adolescent nutrition. In: Nutrition and child development. $2^{\text {nd }}$ edn. Hyderabad. Paras Publishing 2002:115.

3. Anjana Agarwal, Shobha A Udipi. Nutrition and Dietary considerations at different life stages. In: Textbook of human nutrition. $1^{\text {St }}$ edn. New Delhi. Jaypee Brothers medical publishers (P) Ltd 2014: 411.

4. NCD Risk factor Collaboration (NCD-Ric C) Worldwide trends in body mass index, under weight, over weight and obesity from 1975 to 2016: a pooled analysis of 2416 population - based measurement studies in 128.9 million children, adolescents and adults. The Lancet: $10^{\text {th }}$ October, 2017:1-16.
5. Weres ZG, Yebyo HG, Miruts KB, Geesaw HA, Woldehymanof TE. Assessment of adolescents undernutrition level among school students in Eastern Tigray, Ethiopia: A cross sectional study. J Nutr Food Sc 2015;5:402:1-6.

6. Rahman MA, Karim R. Prevalence of stunting and thinness among adolescents in rural area of Bangladesh. Journal of Asian scientific research 2014;4(1):39-46.

7. Vashisht BM, Jyoti, Goel MK. Nutritional status of adolescents in rural and urban Rohtak, Haryana. Health and population perspectives and issues 2009;32(4):19097.

8. Roy S, Barman S, Mondal N, Sen J. Prevalence of stunting and thinness among adolescent girls belonging to the Rajbanshi population of West Bengal, India. J Nepal Paediatr Soc 2016;36(2):147-55.

9. Pal A, Pari AK, Sinha A, Dhara PC. Prevalence of undernutrition and associated factors: A cross sectional study among rural adolescents in West Bengal, India. Int $J$ of Pediatric and adolescent medicine 2017;4:9-18. 